management helpful, not only with handicapped children but with others also.

She brings into a remarkably small compass material which the reader would otherwise have to sift out for himself from very many more detailed texts. The first 95 pages describe the background of groups of handicaps including aspects of their general care and management. In each instance this is followed by reference to the associated oral condition and, finally, the implications and advised dental treatment. It is in relation to the implications and associated oral conditions that the book has value for it will assist the practitioner in selecting those cases that he can manage himself and those that he should refer for advice and/ or treatment to hospitals or special units.

The book is well produced, with 7 pages of photographs together in the centre. There are a few misprints, e.g. 'reasonable' pastes on page 102-but it makes easy reading. There are, however, some criticisms. Firstly the author shows that by virtue of their handicaps the children considered present problems in dental treatment, and yet little emphasis is laid on prevention-mention is made of the use of fluoride tablets, diet, and battery-powered toothbrushes, but surely this is an area in which the general dental practitioner should be encouraged to play a more important part in the 'health team'. Perhaps a future edition may give more attention to the prevention of dental caries. Secondly, the selection of prescriptions for treatment in a text of this size cannot be comprehensive and is likely to represent personal preferences or rule of thumb. It would have been preferable if various approaches to treatment had been mentioned leaving the reader to refer to the bibliography for details of techniques, rather than to enumerate the steps of a single personally preferred procedure.

It is difficult to produce a text that will reach the unaware and persuade them to treat handicapped children, but this book should encourage the interested practitioner to enlarge his experience.

The dental implications of the handicapping conditions mentioned in this book will be of interest to medical practitioners and there should be a place for it in a library open to senior medical students and house staff, as well as on the bookshelf of the general dental practitioner.

Handbook of Clinical Dermatoglyphs. By M. S. Elbualy and Joan D. Schindeler. (Pp. 64; illustrated. \$6.95.) Coral Gables, Florida: University of Miami Press. 1971.

The study of finger and footprint patterns and hand lines, once only of interest to the police and the palmist, is now recognized as a useful diagnostic aid. Though at present this is a tool that seems to be chiefly concerned with mental retardation syndromes, according to L. S. Penrose, 'almost every kind of early growth disturbance which effects the limbs produces some dermatoglyphic effect.' If so, it behoves the paediatrician to make himself au fait with the matter.

This little book assumes the reader to be in total ignorance of this subject, an assumption exactly applicable to this reviewer. After spending a short time looking at the very clear illustrations, however, one at least no longer finds oneself instinctively turning away from any paper presenting dermatoglyphic illustrations.

Dermatoglyphs of the following syndromes are illustrated: trisomies G, D, and E, cri du chat, Turner's, Klinefelter's, XYY, XXYY, de Lange, prenatal rubella, Rubinstein, hypercalcaemia, cerebral gigantism, SmithLemli-Opitz, and Prader-Willi. It is a useful book to have at hand in the clinic.

\section{Epidemiology of Non-Communicable Diseases. British Medical Bulletin, Volume 27, No. 1.} (Pp. 94; illustrated + tables. £2.00.) London: The British Council. 1971.

Epidemiology is a search for patterns in the hope that these will point to causes and thence to prevention. It is therefore no surprise that a volume devoted to epidemiology is of special interest to paediatricians, nor that many of the contributions are directly concerned with childhood. It is opportune that clinical epidemiology should be flowering at a time when it seems probable that the hitherto fragmented medical services for children are approaching a long overdue integration.

Professors Cochrane and Holland review critically the validation of screening procedures and conclude, as others have done, that many of the screening tests advocated, including some widely practised, have little scientific basis. Cervical cytology, for instance, rushed in on the wings of emotion and politics, and these two potent forces are likely to inhibit any objective assessment for many years to come. The short list of 'tests which are considered acceptable' all relate to children, with the sole exception of screening for bacteriuria of pregnancy. Testing newborns for dislocation of the hip and phenylketonuria are acceptable, but it is difficult to reconcile these to the authors' definition of a screening programme as one which 'offers tests to volunteers, using the hope of medical benefits as a means of persuasion'.

Respiratory disease in childhood (Dr. Colley) reviews the relation of social class, air pollution, and childhood smoking to mortality and morbidity from respiratory disorders, both in childhood and in adult life. Though the evidence is not yet conclusive, there are strong hints that chesty children tend to become chesty adults. Whether chest disease in later life can be prevented by more effective prevention and treatment of childhood chest infections remains to be seen. Undoubtedly childhood is the most hopeful time for education about smoking hazards.

Birmingham provides two authoritative contributions to this volume. Professor Knox describes (under a misleading title) the available methods of analysing the distribution of disease in time and space. Professor McKeown and Dr. Record write on early environmental influences on the development of intelligence, a subject of great interest and even greater complexity. Their rather surprising conclusion that abnormalities of pregnancy and labour, birthweight, and length of 